\title{
Vegetable and fruit intake in Australian adolescents: Trends over time and perceptions \\ of consumption
}

\begin{abstract}
The consumption of vegetables and fruit during adolescence is crucial to ensuring adequate intake of the nutrients required to meet the rapid growth that characterises this developmental period. However, significant reductions in vegetable and fruit intake during adolescence have been observed making the promotion of consumption an important health promotion challenge. To monitor progress in this population segment toward meeting recommended intake levels and identifying at-risk groups, the present study assessed changes in Australian adolescents' vegetable and fruit consumption over time and identified the demographic factors associated with meeting recommendations. As individuals who are aware of their diet deficiencies are likely to be more receptive to healthy eating interventions, the present study also assessed adolescents' perceptions of the adequacy of their vegetable and fruit intake and identified the demographic factors associated with correctly perceiving fruit and vegetable intake to be inadequate. Two cross-sectional samples of Western Australian secondary school students aged 12 to 17 years were surveyed in 2009-2010 $(n=1501)$ and 2012-2013 $(n=1406)$. Only $14 \%$ of students at Wave 1 and $13 \%$ at Wave 2 met the recommended guidelines for vegetable intake while $68 \%$ and $71 \%$ met the guidelines for fruit intake. Females had significantly greater odds of failing to meet guidelines for vegetable intake than males. Only $50 \%$ of students correctly identified their vegetable and fruit intake to be inadequate. The observed very low levels of compliance with vegetable intake recommendations suggest that addressing deficiencies in vegetable consumption should be a primary focus of future nutrition interventions. Efforts should also be made to increase adolescents' perceptions of
\end{abstract}


the inadequacy of their intake to optimise the effectiveness of schemes designed to improve vegetable and fruit consumption in this population segment.

Keywords: vegetables; fruit; consumption; adolescents. 


\section{Introduction}

Adolescence is a developmental period characterised by the need for high levels of nutrients to meet rapid growth (Vereecken et al., 2015). The consumption of vegetables and fruit is crucial to ensuring adequate intake of these required nutrients (Boeing et al., 2012), while also providing benefits to long-term health by significantly reducing the risk for a variety of chronic diseases including hypertension, stroke, coronary heart disease, and cancer (Boeing et al., 2012; He, Nowson, Lucas, \& MacGregor, 2007; He, Nowson, \& MacGregor, 2006). Given the health risks associated with inadequate vegetable and fruit intake and the health benefits associated with increased vegetable and fruit intake, promoting a healthy diet has been identified as a global health priority (World Health Organization, 2013). However, despite the implementation in many countries of mass media campaigns promoting vegetable and fruit consumption (e.g., Australia's "Go for $2 \& 5$ ", the US and UK's "5 a day"), intake levels continue to fall well below recommended targets (Micha et al., 2015; Parks et al., 2018), particularly in adolescents. For example in the UK, only $7.9 \%$ of 11 to 18 year olds consume the recommended 5 portions of vegetables and fruit per day (Public Health England, 2018). In US 14 to 18 year olds, just $2.1 \%$ consume the recommended $2-3$ portions of vegetables per day and $8.5 \%$ the recommended $1.5-2$ portions of fruit (Moore, Thompson, \& Demissie, 2017). In Australian 12 to 18 year olds, 2.6\% consume the recommended 5 portions of vegetables per day and $59.4 \%$ the recommended 2 portions of fruit (Australian Bureau of Statistics, 2015).

Adolescence appears to be a particularly critical time for changes in vegetable and fruit consumption (Keast, Fulgoni, Nicklas, \& O'Neil, 2013; Vereecken et al., 2015), with significant reductions in vegetable and fruit intake observed (Albani, Butler, Traill, \& Kennedy, 2017; Herrick, Rossen, Nielsen, Branum, \& Ogden, 2015). This decrease has been 
attributed to a number of factors including the greater influence adolescents exert over their food choices (Albani et al., 2017) and the increase in independence and busy lifestyles seen during this development phase that leads to greater reliance on convenience food (Vereecken et al., 2015). The decline in vegetable and fruit consumption seen during adolescence has also been attributed to reductions in environmental support for healthy eating (Albani et al., 2017). In particular, the transition from primary to secondary school has been associated with significant reductions in both vegetable and fruit intake and the deterioration of children's diet generally (Marks, Barnett, \& Allender, 2015). Research conducted in Australia suggests that compared to primary school environments, secondary school environments are perceived as being less conducive to promoting healthy eating, with fewer healthy eating policies and lower levels of awareness and compliance with these policies (Marks et al., 2015).

In addition to social and physical environmental influences, researchers have identified the importance of psychosocial factors on adolescent eating behaviours (Story, NeumarkSztainer, \& French, 2002). These factors include taste preferences, perceived self-efficacy for healthy eating, attitudes towards healthy eating, and knowledge about healthy eating (Rasmussen et al., 2006; Story et al., 2002). Of interest to the present study is adolescents' perceptions of their dietary habits, more specifically, the extent to which they perceive their vegetable and fruit intake to be adequate or inadequate. Evidence from previous research conducted in adults suggests that a main barrier to increasing consumption of vegetables and fruit is the perception that current intake is adequate (Pollard, Miller, Woodman, Meng, \& Binns, 2009). It follows that efforts to increase vegetable and fruit consumption in adolescents will likely be hampered if those adolescents who are not meeting recommended guidelines incorrectly perceive their intake to be adequate. Conversely, efforts are likely to prove more effective if directed at adolescents who are not meeting recommended guidelines 
but correctly perceive their intake to be inadequate. This makes the identification of adolescents falling into these categories important to health promotion efforts.

\section{Present Study}

The promotion of vegetable and fruit consumption during adolescence is an important health promotion challenge (Carfora, Caso, \& Conner, 2016). Surveillance of trends in adolescent vegetable and fruit consumption via large scale, population-representative surveys is crucial to monitoring progress in this population segment toward meeting recommended intake levels, identifying at-risk groups, and informing public health policy and practice via the development of appropriate and effective interventions. Accordingly, the present study aimed to (i) assess changes in Australian adolescents' vegetable and fruit consumption over time and (ii) identify the demographic factors associated with inadequate intake. As individuals who are aware of their diet deficiencies are likely to be more receptive to healthy eating interventions (Ma, Betts, Horacek, Georgiou, \& White, 2003; Pollard et al., 2009), the present study also sought to (i) assess adolescents' perceptions of the adequacy of their vegetable and fruit intake and (ii) identify the demographic factors associated with correctly perceiving vegetable and fruit intake to be inadequate.

\section{Method}

\section{Design and Procedure}

Data were obtained from the Western Australian component of the National Secondary Students' Diet and Activity (NaSSDA) survey conducted in 2009-2010 (Wave 1; $n=1501$ ) and 2012-2013 (Wave 2; $n=1406$ ). At both waves, a representative cross-sectional sample of Western Australian secondary school students from Years 8 to 11 (aged 12 to 17 years) completed a web-based self-report questionnaire in their regular class groups. A stratified 
two-stage probability design was employed, with schools (government, Catholic and independent) proportionally randomly selected at the first stage of sampling and classes selected within schools at the second stage. Detailed information regarding the methodological procedures of the NaSSDA survey can be found in Morley et al. (2012) and Scully et al. (2017).

\section{Measures}

Vegetable and fruit consumption. Students answered items pertaining to their usual daily vegetable (How many serves of vegetables do you usually eat each day?) and fruit (How many serves of fruit do you usually eat each day?) intake. A serve of vegetables was defined as half a cup of cooked vegetables or one cup of salad vegetables, while a serve of fruit was specified as one medium piece or two small pieces of fruit, or one cup of diced fruit. Images of serving sizes for each were also shown. Responses were recorded on a scale of 1 (I don't eat vegetables/fruit) to 8 ( 6 serves or more). To ensure item means adequately reflected intake, responses were subsequently converted into daily equivalent frequencies (e.g., I don't eat vegetables/fruit $=0$, Less than one serve $=0.5,1$ serve $=1$, and so on).

In Australia it is recommended that children aged 12 to 18 years consume at least 5 servings of vegetables and 2 servings of fruit per day (National Health and Medical Research Council, 2013). For analysis purposes, responses to each item were collapsed into two categories to identify those students meeting recommended guidelines for vegetable and fruit intake $(0=$ did not meet guidelines; 1 = met guidelines).

Perceptions of adequacy of intake. Using a 5-point scale $(1=$ strongly disagree to $5=$ strongly agree), students were asked to indicate the extent to which they agreed with the 
statements I should eat more vegetables and I eat enough fruit. Responses to the latter statement were reverse-coded. For analysis purposes, responses were collapsed into two categories $(1=$ does not believe intake to be inadequate (i.e., responded strongly disagree, disagree, or neither agree nor disagree), 2 = believes intake to be inadequate (i.e., responded agree or strongly agree).

Demographics. Students reported their sex, age, school year level, and residential postcode (used to calculate socio-economic position (SEP) as per the Australian Bureau of Statistics' Socio-Economic Indexes for Areas classification (Australian Bureau of Statistics, 2011)). Remoteness of living location (i.e., metropolitan or regional/remote) was determined using the Australian Statistical Geography Standard (ASGS) (Australian Bureau of Statistics, 2013).

\section{Statistical Analyses}

Data were weighted by education sector, school year level, and sex to ensure comparability to the population of secondary school students in Western Australia (Australian Bureau of Statistics, 2010, 2014). Descriptive analyses were conducted to assess students' compliance with recommended guidelines for vegetable and fruit intake at each wave, overall and by sex. Pearson's chi-square analyses were conducted in SPSS 25 to assess for changes in intake across study waves where data were categorical in nature (i.e., whether participants met or did not meet the recommended guidelines for vegetable and fruit intake at W1 and W2), while independent samples $t$-tests were conducted for continuous data (i.e., mean number of servings of vegetable and fruit consumed per day at W1 and W2). Binary logistic regression (categorical data) and multiple linear regression (continuous data) analyses were conducted on the most recent wave data (i.e., 2012-13) in MPlus 8 to determine the demographic factors 
associated with inadequate intake. Binary logistic regression analyses were also conducted on the most recent wave data to identify the demographic factors associated with students correctly perceiving their vegetable and fruit intake to be inadequate. All regression models included school year level, SEP, and location remoteness as covariates, and controlled for school-level clustering and education sector.

\section{Results}

A total of 1501 students were surveyed in Western Australia at Wave 1 (response rate $=52 \%$ ) and 1406 students were surveyed at Wave 2 (response rate $=54 \%$ ). The unweighted sample profile is presented in Table 1. Slightly more males than females were recruited at Waves 1 and 2 and students in Year 11 were underrepresented in both waves. 
Table 1.

Demographic characteristics (unweighted) of the Wave 1 and Wave 2 samples

$\begin{array}{cc}\text { Wave } 1 & \text { Wave } 2 \\ n=1501 & n=1406\end{array}$

$(\%) \quad(\%)$

\begin{tabular}{|c|c|c|}
\hline \multicolumn{3}{|l|}{ Sex } \\
\hline Male & 55.4 & 51.5 \\
\hline Female & 44.6 & 48.5 \\
\hline \multicolumn{3}{|c|}{ Age (in years) } \\
\hline $\mathrm{M}(S D)$ & $13.91(1.06)$ & $14.39(1.06)$ \\
\hline \multicolumn{3}{|l|}{ Year level } \\
\hline 8 & 35.9 & 26.0 \\
\hline 9 & 30.2 & 34.7 \\
\hline 10 & 25.8 & 22.3 \\
\hline 11 & 8.1 & 17.0 \\
\hline \multicolumn{3}{|c|}{ Socio-economic Position (SEP) } \\
\hline Low & 29.4 & 35.1 \\
\hline Mid & 36.2 & 30.7 \\
\hline High & 34.4 & 34.2 \\
\hline
\end{tabular}




\begin{tabular}{lcc}
\hline Missing* & 1.2 & 0.1 \\
\hline Location & & \\
Metro & 73.8 & 65.4 \\
Regional/remote & 26.2 & 34.6 \\
Missing* & 0.4 & 2.0 \\
\end{tabular}

*Treated listwise 


\section{Vegetable and Fruit Intake}

Table 2 presents the proportion of students consuming recommended amounts of vegetables and fruit. Only $14 \%$ of students at Wave 1 and $13 \%$ of students at Wave 2 reported vegetable consumption consistent with national guidelines, and there was no significant difference across waves observed. Binary logistic regression analyses conducted on the most recent wave data revealed a significant sex difference $(\mathrm{OR}=1.52, \mathrm{CI} 95 \%[1.08,2.14], p=.016)$ with females having significantly greater odds of failing to meet guidelines for vegetable intake than males. Significant differences by year level, location, and SEP were not found (data not shown). Compared to vegetable consumption levels, a greater proportion of students reported fruit consumption levels consistent with national guidelines with $68 \%$ of students at Wave 1 and $71 \%$ of students at Wave 2 meeting recommendations. A significant difference across waves was not observed. Binary logistic regression analyses conducted on the most recent wave data revealed a significant year level difference $(\mathrm{OR}=1.17, \mathrm{CI} 95 \%$ [1.04, 1.33], $p=.012$ ) with those in older year levels having greater odds of failing to meet recommended guidelines for fruit intake than those in younger year levels. Significant differences by sex, location, and SEP were not observed (data not shown).

As vegetable and fruit consumption may have changed over time but not at levels sufficient to influence overall compliance with national guidelines, sensitivity analyses were conducted exploring differences across waves in servings of vegetables and fruit consumed rather than compliance with recommended guidelines. As seen in Table 2, a significant decrease in mean servings of vegetables was observed between Wave 1 and Wave 2 in the overall sample $(t(2646.76)=2.07, p=.038, d=0.08)$. Analyses by sex revealed this difference to be significant in females only $(t(1323)=3.20, p=.001, d=0.18)$. Multiple linear regression analyses conducted on the most recent wave data revealed a significant sex and SEP 
difference in vegetable consumption. Females reported lower vegetable consumption than males $(\mathrm{B}=-.23, S E=.09, \beta=-.07,95 \% \mathrm{CI}=(-.41,-.05), p=.013)$ and those residing in lower SEP areas reported lower vegetable consumption than those living in higher SEP areas $(\mathrm{B}=.04, S E=.02, \beta=.07,95 \% \mathrm{CI}=(.00, .07), p=.028)$. Sensitivity analyses conducted on mean servings of fruit revealed no significant difference in fruit consumption between waves at the overall level or for either sex (see Table 2). Multiple linear regression analyses conducted on the most recent wave data revealed no significant demographic differences in fruit consumption. 
1 Table 2

2 Reported vegetable and fruit intake levels stratified by sex and wave

\begin{tabular}{|c|c|c|c|c|c|c|}
\hline & \multicolumn{2}{|c|}{ Overall } & \multicolumn{2}{|c|}{ Male } & \multicolumn{2}{|c|}{ Female } \\
\hline & W1 & W2 & W1 & W2 & W1 & W2 \\
\hline & $\%$ & $\%$ & $\%$ & $\%$ & $\%$ & $\%$ \\
\hline \multicolumn{7}{|l|}{ Vegetable intake } \\
\hline$\leq 1$ serve & 23.0 & 28.7 & 24.4 & 28.4 & 21.6 & 29.0 \\
\hline 2 serves & 25.9 & 25.4 & 23.5 & 21.3 & 28.3 & 30.1 \\
\hline 3 serves & 24.7 & 20.1 & 25.5 & 21.5 & 23.8 & 18.4 \\
\hline 4 serves & 12.9 & 12.5 & 13.9 & 13.1 & 11.9 & 11.7 \\
\hline $5+$ serves (recommended) & 13.6 & 13.4 & 12.7 & 15.6 & 14.5 & 10.8 \\
\hline Mean servings $(S D)$ & $2.70(1.52)^{\mathrm{a}}$ & $2.58(1.59)$ & $2.68(1.54)$ & $2.69(1.66)$ & $2.72(1.50)^{b}$ & $2.45(1.50)$ \\
\hline
\end{tabular}




\section{Fruit intake}

$\begin{array}{lcccccc}\leq 1 \text { serve } & 31.8 & 29.2 & 31.2 & 30.0 & 32.4 & 28.3 \\ \text { 2+ serves (recommended) } & 68.2 & 70.8 & 68.8 & 70.0 & 67.6 & 71.7 \\ \text { Mean servings }(S D) & 2.33(1.43) & 2.44(1.53) & 2.40(1.47) & 2.53(1.64) & 2.26(1.38) & 2.35(1.39)\end{array}$

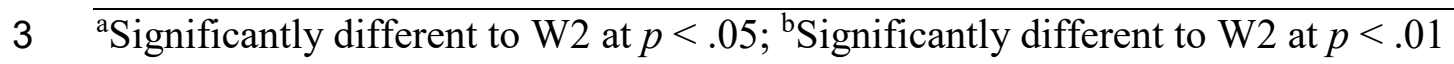


4 Students' Perceptions of the Adequacy of their Vegetable and Fruit Intake

5 Students' perceptions of the adequacy of their vegetable and fruit intake were assessed to

6 determine their levels of awareness of their nutrition deficits (see Table 3). Results are

7 presented for Wave 2 data only as this represents the most recent data collection phase.

8

9 Of those students who reported consuming less than the recommended five daily servings of vegetables, half believed they should consume more and therefore correctly perceived their intake to be deficient. Logistic regressions revealed that females $(\mathrm{OR}=1.81, \mathrm{CI} 95 \%[1.33$, $2.47], p=.002)$ and those from later year levels (OR $=1.19$, CI 95\% $[1.05,1.35], p=.025)$ had greater odds of correctly perceiving their intake to be deficient. SEP (OR $=1.02$, CI 95\% $[0.98,1.06], p=.471)$ and location $(\mathrm{OR}=0.97, \mathrm{CI} 95 \%[0.75,1.27], p=.871)$ did not emerge as significant.

Of those students who reported consuming less than the recommended two daily servings of fruit, half correctly perceived their intake to be deficient. The odds of correctly perceiving fruit intake to be deficient did not differ according to any of the assessed demographic factors. 
29 Table 3

30 Perceptions of adequacy of vegetable and fruit intake by intake levels (W2)

\section{Does not believe intake to Believes intake is \\ be inadequate $^{a} \quad$ inadequate $^{b}$}

\begin{tabular}{lcc} 
& $\%$ & $\%$ \\
\hline Vegetable intake & & \\
$<5$ serves $(n=994)$ & 49.9 & 50.1 \\
$5^{+}$serves $(n=142)$ & 61.3 & 38.7 \\
\hline Fruit intake & & \\
$<2$ serves $(n=338)$ & 49.9 & 50.1 \\
$2^{+}$serves $(n=799)$ & 88.0 & 12.0
\end{tabular}

$31 \overline{{ }^{a} \text { Responded 1, 2, or } 3 \text { on a scale of } 1 \text { (strongly disagree) to } 5 \text { (strongly agree) or reverse- }}$

32 scored equivalent.

$33{ }^{b}$ Responded 4 or 5 on a scale of 1 (strongly disagree) to 5 (strongly agree) or reverse-scored 34 equivalent. 


\section{Discussion}

36 As adolescence is a developmental period characterised by the need for high levels of

37 nutrients to meet rapid growth, it is important that trends in adolescent consumption of

vegetables and fruit are monitored to identify high-risk groups and inform health promotion efforts. In line with previous research (Micha et al., 2015), very few students in the present study met national guidelines for vegetable consumption, with this proportion remaining low across the study waves (i.e., 2009 to 2013). It is particularly concerning that around a quarter of students at both waves reported consuming $\leq 1$ serve of vegetables a day. As a group, females were significantly less likely than males to meet recommended guidelines and sensitivity analyses revealed that when examined as a continuous variable, vegetable consumption significantly decreased between waves in females. Females therefore appear to be a particularly important group to target in efforts to increase adolescent vegetable consumption. It is promising that females in the present study were more likely than males to be aware of their deficient vegetable intake as this likely makes them more receptive to

49 healthy eating interventions.

In contrast to vegetable consumption, a substantially larger proportion of students met recommended national guidelines for fruit consumption. This is likely to be at least partially attributable to the target for fruit ( $\geq 2$ daily servings) being lower and therefore easier to

54 achieve than the target for vegetables ( $\geq 5$ daily servings). The implementation of strategies that increase the availability and accessibility of vegetables, thus making it easier to achieve the higher target, is warranted. Given such strategies have been successfully implemented in

57 Western Australia at the primary school level via the Crunch\&Sip program (blinded for review), similar efforts should be considered for secondary school environments. 
60

61

62

63

64

Students in younger year levels were more likely than those in older year levels to meet guidelines for fruit consumption, supporting previous research that has observed a decrease in fruit intake during adolescence (Larson, Neumark-Sztainer, Hannan, \& Story, 2007). These results highlight the importance of ensuring older adolescents' food environments facilitate the consumption of vegetables and fruit and maintain and promote healthy eating habits. Schools are particularly important environments as children spend a large proportion of their waking hours and consume a substantial number of their meals and snacks in this setting (Biggs, Farrell, Lawrence, \& Johnson, 2014; World Health Organization, 2009).

Given previously observed decreases in the level of environmental support for vegetable and fruit intake from primary to secondary school (Marks et al., 2015), interventions that improve the secondary school food environment are crucial to supporting increases in vegetable and fruit consumption. This may involve increasing the availability, affordability, visibility, variety, and appeal of healthy eating in secondary schools, all of which have been perceived as barriers to healthy eating by adolescents (Krølner et al., 2011; Shepherd et al., 2006).

Environmental change interventions in schools show potential for positively affecting both vegetable and fruit consumption among youth (French \& Stables, 2003; Perry et al., 2004). Specific examples of school-based interventions found to be effective at increasing preference for, and intake of, these foods among youth include hands-on learning opportunities via food preparation classes, cooking classes, and school vegetable gardens (Liquori, Koch, Contento, \& Castle, 1998; McAleese \& Rankin, 2007; Morris \& ZidenbergCherr, 2002; Parmer, Salisbury-Glennon, Shannon, \& Struempler, 2009), reducing the cost of vegetables and fruit sold in cafeterias (French et al., 1997), improving the quality of fruit offered during lunch breaks (Gosliner, 2014), making fruit (and by extension, vegetables) easier and tidier to eat (Wansink, Just, Hanks, \& Smith, 2013), increasing the number of 
85

86

87

88

89

90

91

92

93

94

95

96

97

98

99

100

101

102

103

104

105

106

107

108

109

different vegetable and fruit items that are offered (which serves to increase variety and also the likelihood that a more popular vegetable or fruit is included as an option) (Just, Lund, \& Price, 2012), and offering vegetables with herbed dips (Gosliner, 2014; Savage, Peterson, Marini, Bordi, \& Birch, 2013; Slusser, Cumberland, Browdy, Lange, \& Neumann, 2007).

Such interventions need to be particularly relevant to those residing in lower SEP areas given results from the present study suggest these students consume less vegetables relative to those residing in higher SEP areas.

The aforementioned approaches are likely to be particularly well-received by the $50 \%$ of students who correctly identified their vegetable and fruit consumption to be inadequate.

Results indicated that this perception was more likely to be held by females and older students suggesting programs aimed at increasing vegetable and fruit intake in these population segments may be particularly effective. It is concerning, however, that half of all students who were not consuming the recommended servings of vegetables and/or fruit did not perceive their intake to be inadequate. Previous research in adults suggests that perceived adequacy of current fruit and vegetable intake should be considered when designing nutrition interventions (Pollard et al., 2009). It follows that nutrition education during adolescence is crucial to increasing awareness of national guidelines and the importance of consuming adequate nutrients during this life stage.

The implementation of strategies via school-based interventions has the added advantage of potentially changing social norms. Social norms are an important influence on adolescents' behaviour (Stok, Ridder, Vet, \& Wit, 2014). However, social norms among this population segment tend to be unsupportive of healthy eating (Krølner et al., 2011; Verstraeten et al., 2014). The widespread implementation of programs that involve peers in the delivery of 
110 healthy eating messages may be an effective strategy in establishing new peer norms (Croll,

111 Neumark-Sztainer, \& Story, 2001), thereby increasing the importance of adequate vegetable

112 and fruit intake in this demographic group. Previous research suggests that descriptive norm

113 messages are capable of improving adolescents' perceptions of their peers' eating habits and

114 positively influencing fruit intake (Stok et al., 2014). These social norm based interventions

115 may be particularly beneficial for the students in the present study who did not consume the

116 recommended servings of vegetables and fruit and did not believe they needed to increase

117 their intake. For these adolescents, increasing their awareness of the inadequacy of their

118 vegetable and fruit intake by invoking descriptive norms may be key to increasing their

119 consumption of these foods and reducing the normalcy of non-consumption in this population

120 segment.

121

122 With respect to policy, research in the US has shown that students attending schools with a

123 larger number of policies that promote healthy eating show improved dietary behaviours

124 relative to students attending schools with fewer policies (Nanney et al., 2014). This suggests

125 that a crucial step in increasing vegetable and fruit consumption will be ensuring that school compliance with national healthy eating guidelines is mandated. In Australia, for example,

127 while national guidelines and resources for implementing healthy canteens in schools are available to all schools, conforming to these guidelines is not mandatory in all Australian

129 jurisdictions. As a result, there are significant differences in policy implementation and

130 adherence (Marks et al., 2015), leading to inconsistencies between schools and inequities in

131 the health environment. Recent evidence indicates that teachers are receptive to programs that

132 aim to increase vegetable intake, with some teachers already employing their own strategies

133 to address inadequate consumption (Sharp et al., 2017). Mandated policies are therefore

134 likely to be well received by those most likely to be involved in their implementation. This is 


\section{Conclusion}

155 Consistent with previous research, very few students in the present study met national 156

a promising finding given teachers' attitudes and behaviours to vegetable intake are likely to be important in efforts that aim to address deficits in vegetable intake as a result of their role as primary caregiver while children are at school (Mita, Li, \& Goodell, 2013; Sharp et al., 2017).

The present study has some limitations that need to be taken into account when interpreting the findings. First, these data are based on self-report and social desirability bias may have resulted in students inflating their estimates of vegetable and fruit intake. Second, although representative samples were recruited at each wave, matched samples may have reduced the risk of sampling bias. Third, current Australian guidelines for adolescent vegetable intake differ slightly between males and females with 5.5 servings per day recommended for males and 5 servings per day recommended for females. To keep response options as simple as possible, half servings were not assessed. As such, analyses involving the proportions of students meeting recommended vegetable guidelines did not take into account the additional half serve recommended for males. Finally, the items used to assess student perceptions of the adequacy of their vegetable and fruit intake were worded in opposition. Although this was an intentional means of reducing acquiescence bias, it may have also led to confusion and erroneous reporting. guidelines for vegetable consumption while a substantially larger proportion of students met recommended national guidelines for fruit intake. While these findings highlight the importance of a continued focus on the promotion of vegetable and fruit consumption, the very low levels of compliance with vegetable intake recommendations suggest that 
160 addressing deficiencies in vegetable consumption should be a primary focus of future

161 nutrition interventions. Multiple component interventions that combine classroom curricula

162 with environmental changes that increase the availability and appeal of vegetables and fruit,

163 and provide increased opportunities for adolescents to learn about vegetables and fruit,

164 appear to hold most promise for increasing consumption. Paying increased attention to

165 adolescents' food environments, addressing potential barriers to vegetable and fruit

166 consumption, and mandating healthy eating policies may help maintain progress on fruit

167 intake and improve vegetable intake. Efforts must also be made to increase adolescents'

168 perceptions of the inadequacy of their intake to optimise the effectiveness of schemes

169 designed to improve vegetable and fruit consumption in this population segment. 


\section{References}

172 Ahern, S. M., Caton, S. J., Blundell, P., \& Hetherington, M. M. (2014). The root of the 173 problem: increasing root vegetable intake in preschool children by repeated exposure and flavour flavour learning. Appetite, 80, 154-160. doi:10.1016/j.appet.2014.04.016

Albani, V., Butler, L. T., Traill, W. B., \& Kennedy, O. B. (2017). Fruit and vegetable intake: Change with age across childhood and adolescence. British Journal of Nutrition, 117(5), 759-765.

Australian Bureau of Statistics. (2010). Schools Australia, 2009. Catalogue no. 4221.0. Canberra: Australian Bureau of Statistics.

Australian Bureau of Statistics. (2011). SEIFA Census of Population and Housing: SocioEconomic Indexes for Areas (SEIFA), Australia, 2011. (Cat. no. 2033.0.55.001). Canberra: ABS;

Australian Bureau of Statistics. (2013). 1270.0.55.005 - Australian Statistical Geography Standard (ASGS): Volume 5 - Remoteness Structure, July 2011 Retrieved from http://www.abs.gov.au/ausstats/abs@.nsf/mf/1270.0.55.005?OpenDocument

Australian Bureau of Statistics. (2014). Schools Australia, 2013. Catalogue no. 4221.0. Canberra: Australian Bureau of Statistics.

Australian Bureau of Statistics. (2015). Table 17.3. Children's daily intake of fruit and vegetables and main type of milk consumed, proportion of persons. Canberra: Australian Bureau of Statistics. Retrieved from http://www.abs.gov.au/AUSSTATS/abs@.nsf/DetailsPage/4364.0.55.001201415?OpenDocument.

Biggs, J. S., Farrell, L., Lawrence, G., \& Johnson, J. K. (2014). Applying process mapping and analysis as a quality improvement strategy to increase the adoption of fruit, 

vegetable, and water breaks in Australian primary schools. Food and Media, 15(2), 199-207. doi:10.1177/1524839913505291

Boeing, H., Bechthold, A., Bub, A., Ellinger, S., Haller, D., Kroke, A., . . Watzl, B. (2012). Critical review: Vegetables and fruit in the prevention of chronic diseases. European Journal of Nutrition, 51(6), 637-663.

Carfora, V., Caso, D., \& Conner, M. (2016). Randomized controlled trial of a messaging intervention to increase fruit and vegetable intake in adolescents: Affective versus instrumental messages. British Journal of Health Psychology, 21(4), 937-955.

Croll, J. K., Neumark-Sztainer, D., \& Story, M. (2001). Healthy eating: What does it mean to adolescents? Journal of Nutrition Education, 33(4), 193-198.

French, S. A., \& Stables, G. (2003). Environmental interventions to promote vegetable and fruit consumption among youth in school settings. Preventive Medicine, 37(6), 593610.

French, S. A., Story, M., Jeffery, R. W., Snyder, P. A. T., Eisenberg, M., Sidebottom, A., \& Murray, D. (1997). Pricing strategy to promote fruit and vegetable purchase in high school cafeterias. Journal of the American Dietetic Association, 97(9), 1008-1010.

Gosliner, W. (2014). School-level factors associated with increased fruit and vegetable consumption among students in California middle and high schools. Journal of School Health, 84(9), 559-568.

He, F. J., Nowson, C. A., Lucas, M., \& MacGregor, G. A. (2007). Increased consumption of fruit and vegetables is related to a reduced risk of coronary heart disease: Metaanalysis of cohort studies. Journal of Human Hypertension, 21(9), 717-728.

He, F. J., Nowson, C. A., \& MacGregor, G. A. (2006). Fruit and vegetable consumption and stroke: Meta-analysis of cohort studies. The Lancet, 367(9507), 320-326. 
Herrick, K. A., Rossen, L. M., Nielsen, S. J., Branum, A. M., \& Ogden, C. L. (2015). Fruit consumption by youth in the United States. Pediatrics, 136(4), 664-671. doi:10.1542/peds.2015-1709

Just, D. R., Lund, J., \& Price, J. (2012). The role of variety in increasing the consumption of fruits and vegetables among children. Agricultural and Resource Economics Review, $41(1), 72-81$.

Keast, D. R., Fulgoni, V. L., Nicklas, T. A., \& O'Neil, C. E. (2013). Food sources of energy and nutrients among children in the United States: National Health and Nutrition Examination Survey 2003-2006. Nutrients, 5(1), 283-301.

Krølner, R., Rasmussen, M., Brug, J., Klepp, K. I., Wind, M., \& Due, P. (2011). Determinants of fruit and vegetable consumption among children and adolescents: a review of the literature. Part II: qualitative studies. International Journal of Behavioral Nutrition and Physical Activity, 8(1), 112.

Larson, N. I., Neumark-Sztainer, D., Hannan, P. J., \& Story, M. (2007). Trends in adolescent fruit and vegetable consumption, 1999-2004: Project EAT. American Journal of Preventive Medicine, 32(2), 147-150.

Liquori, T., Koch, P. D., Contento, I. R., \& Castle, J. (1998). The cookshop program: Outcome evaluation of a nutrition education program linking lunchroom food experiences with classroom cooking experiences. Journal of Nutrition Education, $30(5), 302-313$.

Ma, J., Betts, N. M., Horacek, T., Georgiou, C., \& White, A. (2003). Assessing stages of change for fruit and vegetable intake in young adults: A combination of traditional staging algorithms and food-frequency questionnaires. Health Education Research, $18(2), 224-236$. 
244 Marks, J., Barnett, L. M., \& Allender, S. (2015). Change of school in early adolescence and adverse obesity-related dietary behavior: A longitudinal cohort study, Victoria, Australia, 2013-2014. Preventing Chronic Disease: Public Health Research, Practice, and Policy, 12. doi:10.5888/pcd12.150042

McAleese, J. D., \& Rankin, L. L. (2007). Garden-based nutrition education affects fruit and vegetable consumption in sixth-grade adolescents. Journal of the American Dietetic Association, 107(4), 662-665.

Micha, R., Khatibzadeh, S., Shi, P., Andrews, K. G., Engell, R. E., \& Mozaffarian, D. (2015). Global, regional and national consumption of major food groups in 1990 and 2010: A systematic analysis including 266 country-specific nutrition surveys worldwide. $B M J$ Open, 5(9), e008705.

Mita, S. C., Li, E., \& Goodell, L. S. (2013). A qualitative investigation of teachers' information, motivation, and behavioral skills for increasing fruit and vegetable consumption in preschoolers. Journal of Nutrition Education and Behavior, 45(6), 793-799.

Moore, L. V., Thompson, F. E., \& Demissie, Z. (2017). Percentage of youth meeting federal fruit and vegetable intake recommendations, Youth Risk Behavior Surveillance System, United States and 33 states, 2013. Journal of the Academy of Nutrition and Dietetics, 117(4), 545-553. doi:10.1016/j.jand.2016.10.012

Morley, B., Scully, M., Niven, P., Baur, L. A., Crawford, D., Flood, V., . . . for the NaSSDA Study Team. (2012). Prevalence and socio-demographic distribution of eating, physical activity and sedentary behaviours among Australian adolescents. Health Promotion Journal of Australia, 23(3), 213-218. doi:10.1071/HE12213 
Morris, J. L., \& Zidenberg-Cherr, S. J. (2002). Garden-enhanced nutrition curriculum improves fourth-grade school children's knowledge of nutrition and preferences for some vegetables. Journal of the American Dietetic Association, 102, 91-93.

Nanney, M. S., MacLehose, R., Kubik, M. Y., Davey, C. S., Coombes, B., \& Nelson, T. F. (2014). Recommended school policies are associated with student sugary drink and fruit and vegetable intake. Preventive Medicine, 62, 179-181.

National Health and Medical Research Council. (2013). Eat for health: Australian dietary guidelines. Canberra, Australia: NHMRC. Retrieved from https://www.eatforhealth.gov.au/sites/default/files/content/n55_australian_dietary_gui delines.pdf.

Parks, C. A., Blaser, C., Smith, T. M., Calloway, E. E., Oh, A. Y., Dwyer, L. A., . . Yaroch, A. L. (2018). Correlates of fruit and vegetable intake among parents and adolescents: Findings from the Family Life, Activity, Sun, Health, and Eating (FLASHE) study. Public Health Nutrition. doi:10.1017/S1368980018000770

Parmer, S. M., Salisbury-Glennon, J., Shannon, D., \& Struempler, B. (2009). School gardens: an experiential learning approach for a nutrition education program to increase fruit and vegetable knowledge, preference, and consumption among second-grade students. Journal of Nutrition Education and Behavior, 41(3), 212-217.

Perry, C. L., Bishop, D. B., Taylor, G. L., Davis, M., Story, M., Gray, C., . . Harnack, L. (2004). A randomized school trial of environmental strategies to encourage fruit and vegetable consumption among children. Health Education \& Behavior, 31(1), 65-76.

Pollard, C., Miller, M., Woodman, R. J., Meng, R., \& Binns, C. (2009). Changes in knowledge, beliefs, and behaviors related to fruit and vegetable consumption among Western Australian adults from 1995 to 2004. American Journal of Public Health, 99(2), 355-361. doi:10.2105/AJPH.2007.131367 
292 Public Health England. (2018). National Diet and Nutrition Survey: Results from Years 7-8 (combined) of the Rolling Programme (2014/15 to 2015/16). Online data tables.

294

295 London: Public Health England.

Rasmussen, M., Krølner, R., Klepp, K. I., Lytle, L., Brug, J., Bere, E., \& Due, P. (2006). Determinants of fruit and vegetable consumption among children and adolescents: A review of the literature. Part I: quantitative studies. International Journal of Behavioral Nutrition and Physical Activity, 3(1). doi:10.1186/1479-5868-3-22

Savage, J. S., Peterson, J., Marini, M., Bordi, P. L., \& Birch, L. L. (2013). The addition of a plain or herb-flavored reduced-fat dip is associated with improved preschoolers' intake of vegetables. Journal of the Academy of Nutrition and Dietetics, 113(8), 10901095. doi:10.1016/j.jand.2013.03.013

Scully, M., Morley, B., Niven, P., Crawford, D., Pratt, I. S., Wakefield, M., \& for the NaSSDA Study Team. (2017). Factors associated with high consumption of soft drinks among Australian secondary school students. Public Health Nutrition. doi: $10.1017 / \mathrm{S} 1368980017000118$

Sharp, G., Pettigrew, S., Wright, S., Pratt, I. S., Blane, S., \& Biagioni, N. (2017). Potential inclass strategies to increase children's vegetable consumption. Public Health Nutrition. doi:10.1017/S136898001700012X

Shepherd, J., Harden, A., Rees, R., Brunton, G., Garcia, J., Oliver, S., \& Oakley, A. (2006). Young people and healthy eating: A systematic review of research on barriers and facilitators. Health Education Research, 21(2), 239-257.

Slusser, W. M., Cumberland, W. G., Browdy, B. L., Lange, L., \& Neumann, C. (2007). A school salad bar increases frequency of fruit and vegetable consumption among children living in low-income households. Public Health Nutrition, 10(12), 14901496. 
317 Stok, F. M., Ridder, D. T., Vet, E., \& Wit, J. B. (2014). Don't tell me what I should do, but

318

319

320

321

322

323

324

325

326

327

328

329

330

331

332

333

334

335

336

337

338

339

340

341 what others do: The influence of descriptive and injunctive peer norms on fruit consumption in adolescents. British Journal of Health Psychology, 19(1), 52-64.

Story, M., Neumark-Sztainer, D., \& French, S. (2002). Individual and environmental influences on adolescent eating behaviors. Journal of the Academy of Nutrition and Dietetics, 102(3), S40-S51.

Vereecken, C., Pedersen, T. P., Ojala, K., Krølner, R., Dzielska, A., Ahluwalia, N., .. Kelly, C. (2015). Fruit and vegetable consumption trends among adolescents from 2002 to 2010 in 33 countries. The European Journal of Public Health, 25(suppl 2), 16-19.

Verstraeten, R., Van Royen, K., Ochoa-Avilés, A., Penafiel, D., Holdsworth, M., Donoso, S., ... Kolsteren, P. (2014). A conceptual framework for healthy eating behavior in Ecuadorian adolescents: A qualitative study. PLoS One, 9(1). doi:10.1371/journal.pone.0087183.g001

Wansink, B., Just, D. R., Hanks, A. S., \& Smith, L. E. (2013). Pre-sliced fruit in school cafeterias: children's selection and intake. American Journal of Preventive Medicine, 44(5), 477-480.

Wild, V., Graaf, C., \& Jager, G. (2015). Efficacy of repeated exposure and flavour-flavour learning as mechanisms to increase preschooler's vegetable intake and acceptance. Pediatric Obesity, 10(3), 205-212. doi:10.1111/ijpo.244

World Health Organization. (2009). Health promoting schools: A framework for action. Retrieved from http://www.wpro.who.int/health_promotion/documents/docs/HPS_framework_for_act ion.pdf

World Health Organization. (2013). Global action plan for the prevention and control of noncommunicable diseases 2013-2020. Geneva: World Health Organization. 
